\title{
DETECTING WATER IMPREGNATION DEFECTS OF HONEYCOMB SANDWICH COMPOSITES BY USING INFRARED THERMOGRAPHY
}

\author{
$\underline{\text { Koo Ahn Kwon }}{ }^{1}$, Man Yong Choi ${ }^{1}$, Hee Sang Park ${ }^{2}$, Jeong Hak Park ${ }^{1}$ and Won Jae Choi ${ }^{1}$ \\ ${ }^{1}$ Korea Research Institute Standards and Science, Korea' \\ ${ }^{2}$ Korea Research Institute of Smart Material and Structures System, Korea
}

\begin{abstract}
More Honeycomb sandwich composite are used for the aerospace industry. Advantages of Honeycomb sandwich composites are that it can withstand large load and is lightweight.

However, the nature of aviation makes these materials exposed to high temperature and high moisture conditions depending on climate, location, and altitude. Therefore, the molecular arrangement and chemical and mechanical properties of composite materials can be changed under these conditions. As a result, water impregnation defects are created.

This study evaluated the possibility of detecting the moisture-impregnating defects of CFRP and GFRP honeycomb structure sandwich composite materials, which are composite materials for the aircraft, by using an active infrared thermography technology among non-destructive testing methods.
\end{abstract}

